\section{SOI: 1.1/TAS DOI: 10.15863/TAS International Scientific Journal Theoretical \& Applied Science}

p-ISSN: 2308-4944 (print) e-ISSN: 2409-0085 (online)

Year: $2015 \quad$ Issue: 08 Volume: 28

Published: $30.08 .2015 \quad$ http://T-Science.org

SECTION 21. Pedagogy. Psychology. Innovations in the field of education.
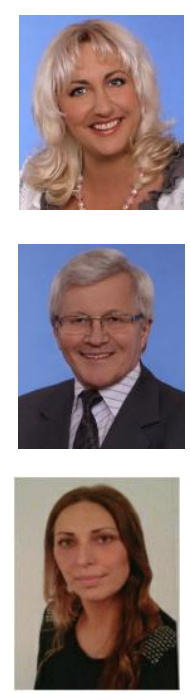

Dorota Kozlowska

Ph.D., Nicolaus Copernicus in Torun, Faculty of Earth Sciences, Poland kozlowska_dorotka@wp.pl

Wojciech Ryszkowski Associate Professor, the Józef Piłsudski Academy of Physical Education in Warsaw, Poland w.ryszkowski@wp.pl

Anna Browko Scientific circles Theory and Methodology of the physical education the College of

Physical Education and Tourism in Białystok, Poland mianserin@vp.pl

\title{
THE REASONS AND FACTORS BEHIND WOMEN'S PARTICIPATION IN AEROBICS CLASSES
}

Abstract: The publication aimed at recognizing and comparing the reasons and factors which foster undertaking aerobics classes among women in two age groups. A diagnostic survey and a questionnaire were used for this purpose. The survey was conducted among 48 women who do aerobics. The women were divided into two age groups. The analysis of the survey results showed that younger women were more motivated to do aerobics (8.99) in relation to women over 40 (8.17). The factors motivating women to do aerobics were less significant among younger women (9.14) than older women (9.21).

Key words: aerobics, reasons, factors, women.

Language: Russian

Citation: Kozlowska D, Ryszkowski W, Browko A (2015) THE REASONS AND FACTORS BEHIND WOMEN'S PARTICIPATION IN AEROBICS CLASSES. ISJ Theoretical \& Applied Science 08 (28): 47-55.

Soi: http://s-o-i.org/1.1/TAS-08-28-7 Doi: crossef http://dx.doi.org/10.15863/TAS.2015.08.28.7

\section{МОТИВЫ И ФАКТОРЫ УЧАСТИЯ ЖЕНЩИН В АЭРОБИКЕ}

Аннотация: Целью исследования было изучение и сравнение мотивов и факторов способствующих росту занятий аэробикой среди женщин в двух возрастных группах. Для реализации цели использовань диагностическое зондирование и опросный лист анкеты. Исследование проведено среди 48 женщин занимающихся аэробикой. Исследуемых поделили на две возрастные группь. Анализ результатов исследования показал, что молодые женщины были более мотивированы к занятиям (8,99), в отношении к женщинам после 40 лет $(8,17)$. Факторы влияющие на мотивацию были меньше среди молодых женщин $(9,14)$ в отношении к женшинам старше 40 лет $(9,21)$.

Ключевые слова: аэробика, мотивы, факторы, женщины.

\section{Введение}

Активный отдых как время провождение это идеальное предложение для улучшения самочувствия, здоровья и координации. Мировая Организация Здоровья рекомендует ежедневные занятия в виде ходьбы, бега или аэробики. Физическая и рекреационная активность становится не только модной [4, с. 82], но также становится требованием или определением высокого статуса, профессии, должности, способа и стиля жизни. Участие в спортивных занятиях - это одно из критериев центральных оценок государственных служб в США и отдельных странах Европы [7, с. 118].

Аэробика - это хорошо известная форма двигательной активности имеющая широкую гамму упражнений, ведущихся инструкторами фитнесса. Благодаря распространению этой формы активности всё больше женщин выбирает аэробику, ориентируясь различными мотивами и факторами.

Большая заслуга средств массовой информации - это распространение информации об отрицательных следствиях пассивного стиля жизни. Всё больше говорится о болезнях 
связанных с сидящей работой. Особенный нажим - ложится на борьбу с полнотой. Мотивы связанные с проблемами развития цивилизации и вероятно частое просвещение общества об эффектах небрежности, к собственному телу, мотивируют женщин в разном возрасте к ежедневной двигательной активности. Опасение перед потерей красоты, силуэта и хорошего самочувствия располагают человечество к поиску адэкватных форм активности при определённой необходимости. Необходимости и мотивы могут изменяться как в зависимости от среды, в которой мы живём, так и от возраста. Молодые женщины обремененные семейной жизнью, профессиональной работой и собственным развитием, вероятно будут иметь другие необходимости, в отношении к женщинам, для которых профессиональная и семейная ситуация последовательно подлежит стабилизации. Трудно однако определить, какие мотивы и факторы способствуют участию в занятиях аэробики среди женщин в разном возрасте.

Мотивы и факторы участия в аэробике. Мотивировка - это совокупность факторов побуждающих к действию и влияющих на его направление и интенсивность [2; 5]. Мотив возникает из двух главных причин: в соединении c необходимостью удовлетворения основных нужд, или в соединении с выполнением заданий, которые мы сами себе ставим. Мотивировку делим на: внешнюю и внутреннюю [3, с. 163 164]. Внешняя мотивировка - это иначе называемая набросанная мотивировка, напр. через родителей. Действует она так долго, как долго боимся последствия. Внутренняя мотивировка вытекает из наших собственных нужд, увлечений или суждений. Это мотивировка устойчивая, дающаяся шанс на активность в течение целой жизни [11].

Существует много мотивов, которые располагают к активному времяпровождению. Одни авторы выделяют следующие роды мотивов двигательной активности: активность гедонистическая; релаксационная; здоровьегигиеническая; познавательно-воспитательная; эмоциональная; формирования собственного характера; общественно-товарищеская; соревнования и соперничества; честолюбивая и модная [1, с. 55-58]. Затем другие авторы ссылаясь на Winiarskiego, представили семь типов мотивировки людей занимающихся двигательной активностью: активность гедонистическая; релаксационная; здоровье гигиеническая; общественно - товарищеская; искателя приключений; самолюбивая и познавательно - воспитательная [3, с.124-125]. Мотивировки не полагается рассматривать обособленно. Факторы двигательной активности имеют огромное значение в удовлетворении мотивов.

Факторы активного поведения в свободное время. Активное времяпровождение зависимо от множества разнородных факторов. В литературе встречаются разнородные группы факторов, напр.: социально - экономические и общественные; экологические и личностные [9, с. 2]. Другую классификацию факторов влияющих на активные поведения показал R. Winiarski, обменивая: биологические, психические, общественно - демографические, экономические [12]. Зато J. Gracz, T. Sankowski утверждают, что фактор решающий о принятии рекреационной деятельности является коллективной, групповой активностью. Общественная группа может влиять на рекреационные отношения личности, которые постоянно подчиняются оценке по установленным групповым образцам. Последствия такой оценки соответствуют положительным и отрицательным реакциям коллектива ввиду отдельных её членов. Очередной фактор влияющий на род принятия двигательной активности - центральное положение, то есть самая большая ценность для данной личности [3, с. 208-209]. В литературе также встречается ещё другая классификация факторов: психологические, биологичные и другие, такие как: возраст, пол, образование, ступень урбанизации места жительства, навыки приобретенные дома, спортивные умения, занятие спортом в прошлом, физическое воспитание в школе [1, с.175].

Подытоживая, можно констатировать, что факторы, которые в главной мере увеличивают увлечение и участие в рекреационной активности это: жизненная стабилизация, положительные спортивные опыты вынесенные с детства, принятие молодыми людьми проздоровых образцов поведений. Двигательная активность играет важную роль в удовлетворении разных нужд, таких как ннеобходимость релакса, психофизической активности, общественных контактов, контактов с природой и т.д. С факторами точно связанны причины, иначе говоря, мотивы принятия двигательной активности, которые в большой мере решают о принятии активности в свободное время.

Исследования над мотивировкой к аэробике. Исследования переведённые в 2009г. среди женщин в разном возрасте занимающихся аэробикой проявили, что среди главных мотивов выбора аэробики как формы двигательной активности были - необходимость движения (40\%), улучшение силуэта (30\%) и положительный эффект упражнений в отношении к смягчению стресса (20\%) [13]. Исследования опубликованны в 2011г. касающееся мотивировки выбора спортивной аэробики, 
проведённые среди 100 лотерийно подобранных $\begin{array}{llll}\text { студентов } & \text { с } & 20 & \text { учебных }\end{array}$ заведений/университетов, технических учебных заведений и АФВ проявили, что выбор занятий спортивной аэробики был предложением академических учителей. Самыми существенными мотивами выбора аэробики среди участников были: движение с музыкой (59\%), оздоровительные достоинства, двигательная активность - улучшение силуэта и физической координации (55\%), удовольствия вытекающие из соперничества и эмоции связанные с аэробикой (54\%) [8]. Другие исследования касающиеся оздоровительных мотивов упражняющихся в фитнесс клубах, опубликованные в 2012г. проявили, что здоровье и физическая координация составляли главные мотивы участия в двигательных занятиях женщин. Важны были мотивы связанные с заботой и улучшением вида своего тела. Значительно меньше были интерперсональные соотношения и разгружение стресса. Сущность оздоровительной мотивировки росла с возрастом респонденток. Однако мотив здоровья для внешнего вида тела падал вместе с ростом уровня воспитания женщин. Для женщин замужних более существенные были оздоровительные мотивы, в отношении к незамужним женщинам, для которых существенные были мотивы улучшения вида тела [6]. Результаты исследований проведённых среди женщин в разном возрасте, участвующих в занятиях аква фитнесса проявили, же главные мотивы принятия этих занятий среди женщин старше 26 лет касались здоровья, отдыха - хорошего самочувствия и эстетики - вида, стройной фигуры. Молодые женщины направлялись гедонистическими мотивами - пребыванием в воде для удовольствия [10]. Как можно заметить, частый мотив выбора этой формы активности улучшение вида, силуэта и хорошего самочувствия.

\section{Материалы и методы.}

Цель исследования: оценка мотивов и факторов принятия активности в занятиях аэробики. Предполагалось, что вероятно, главным мотивом будут мотивы здоровья гигиенические (украшание тела и сохранение красивого силуэта), решающим же фактором об активности будут факторы административно экономические, а среди них доступность занятий.

Сформированы следующие исследовательские вопросы:

1. Которые из мотивов ключевые в посещении занятий аэробики среди обоих возрастных групп?

2. Какие факторы ведущие среди участниц занятий аэробики в обоих возрастных группах?
Для реализации цели использован метод диагностического зондирования. Анкетные исследования применены для оценки мотивов и факторов активности в аэробике. Респондентки оценивали сущность мотивов и факторов в масштабе с 0 до 10 пкт., где 10 обозначало самую высокую ценность.

\section{Характеристика исследуемых.}

Исследования проведены в трёх фитнесс клубах в Белостоке в 2014г. К исследованиям приступило 48 женщин, по 24 человека в каждой возрастной группе. Респондентки в большинстве владели высшим магистерским (62,5\%) и дипломным образованием (25\%). Другое образование имело 6 респонденток составляющих $\quad 12,5 \% \quad$ совокупности. Исследуемые, главным образом проживали в городе $(87,5 \%)$, немногочисленные женщины $(12,5 \%)$ проживали в деревнях.

Респондентки в $21 \%$ посещали занятия аэробики около 2 лет, $17 \%$ посещали около 8 месяцев. Большее число респонденток (62\%) посещало аэробику около 6 месяцев. Наибольше женщин посещало занятия аэробикой 2 раза в неделю $(41 \%)$, и 1 раз в неделю (33\%). Немного больше $1 / 4$ исследуемых (26\%) участвовала в занятиях аэробики 3 раза в неделю.

Результаты исследований - мотивировки к аэробике приведены в табл. 1 .

\section{Мотивы} оздоровительные

\section{гигиенические.}

Женщины в обоих возрастных группах имели одинаковые мнения касающиеся мотивов оздоровительно - гигиенических. Все женщины на первом месте ставили хорошее здоровье, физическую координацию, красивый силуэт, лучшую красоту, хорошее самочувствие, необходимость отдыха и релакса.

Мотивы общественно - товарищеские.

Женщины до 40 лет оценили на больше, чем 9 пкт. из 10 возможных, общественных товарищеских мотивов. В случае женщин после 40 лет мотивы функционирования в среде других людей, навязывания товарищеских контактов имели меньшее значение по крайней мере о 1,5 пункта в отношении к младшим подругам.

Также оказалось, что молодые женщины большой вес $(9,85)$ привязывали к общественным - товарищеским мотивам в отличии от женщин после 40 лет $(8,19)$.

\section{Мотивы формирования характера.}

Взрослых и молодых женщин мотивировала возможность формирования характера: решимость, чувство собственной ценности, стойкость, устойчивость, систематичность, вера в собственные возможности и мужество. Оценки мотивов были похожие среди женщин в разном возрасте /от почти 10 пунктов до 8,13 пункта/. Только в случае выдвижения более трудных 
целей мнения женщин были более дифференцированы.

Исследования показали, что молодые женщины привязывали немного большее внимание $(9,33)$ к формированию характера через занятия, по отношению к старшим женщинам $(8,89)$.

Мотивы активности - гедонистические.

Главным мотивом среди младших участниц исследований была привлекательность и мода. Старшие участницы оценили этот мотив на 8,9 пкт. В мнении младших участниц значимым мотивом была биологическая необходимость движения. Для старших участниц исследования, этот мотив имел меньшее значение $(7,18)$. Осуществление эстетических нужд и удовольствие с эстетики жизни и действия были тоже более значимыми мотивами среди младших участниц занятий $(8,19)$ в отношении к старшим женщинам $(5,87)$.

Примечательно, что молодые женщины занимающиеся аэробикой привязывали больший вес к мотивам активности - гедонистическим $(9,26)$, по отношению к старшим женщинам, для которых эти мотивы были менее существенны 7,02 пункта.

\section{Честолюбивая мотивировка.}

Молодые женщины оправдывались для самих себя и этот мотив был для них более важный $(9,89)$, чем для старших женщин $(8,54)$. Большая разница выступила в случае мнения о мотивировке приобретения общественного одобрения. Этот мотив был значительно более существенен среди младших респонденток $(9,78)$, чем в случае старших подруг $(5,98)$. Тоже большая разница составляющая свыше 3 пункта. заметная была в случае достижений совершенства на показ для других. В этом случае младшие женщины оценили этот вопрос как очень важный, же старшее привязывали к нему меньшее внимание. Такие же мнения выразили все женщины $($ по 7,13) в случае мотива оценения собственного эго.

Подытоживая честолюбивые мотивы можно констатировать, что были они на много более важны среди молодых $(9,09)$, чем среди старших женщин $(6,95)$.

\section{Релаксационный мотив.}

В мнений старших $(9,56)$ и младших $(9,46)$ участниц исследования аэробика как релаксационный мотиватор разгружал стресс и напряжённость. Значительные разницы заметны в случае мотивировки „внутреннего очищения”. Младшие участницы занятий аэробикой указали, что этот мотив был для них значительно более важный $(9,50)$ в отношении к старшим участницам $(6,45)$. Очень важным мотивом для женщин до 40 лет $(9,13)$ был отдых. Похоже ответили женщины после 40 лет $(8,89)$. Для обоих исследуемых группах аэробика была одной из самых важных форм бегства от беспокойств и забот ежедневного дня (молодые женщины: 8,98; старшие женщины: 8,99). В мнении молодых женщин очень важным релаксационным мотивом была профилактика утомления $(8,89)$, же в оценке старших женщин этот мотив был немного меньше существенный $(8,13)$. В оценке женщин до 40 лет занятия освобождали от набросанных общественных связей $(8,89)$. Для женщин после 40 лет этот мотив имел немного меньшее значение.

Мотивы релаксационные для молодых женщин имели немного меньшее значение $(8,13)$ по отношению к женщинам после 40 лет $(9,20)$.

Мотивы познавательно - воспитательные.

Мотивы получения новых умений, навыков активного стиля жизни и мотивы получения знания о возможностях человеческой природы оценивались высоко в обоих исследуемых группах. Мотив развития собственных увлечений и пристрастий был значительно выше оценен через младшую группу $(9,05)$ чем старшую $(8,15)$. Также более существенным среди молодых женщин был мотив собственного совершенствования. Углубление знания о ценности здоровья для обоих исследуемых групп был похоже существенный. Однако мотив познания и обучения нового был значительно выше оценен респондентнками после 40 лет.

Подытоживая сходства и различия можно заметить, что мотивы имели похожее значение среди женщин до 40 лет $(8,84)$ и после 40 лет $(8,74)$.

Мода - аэробика.

Анализ результатов показал, что молодые женщины высоко оценили $(9,89)$ активный стиль жизни как самый модный. Женщины после 40 лет привязывали к этому немного меньшее внимание $(9,32)$. Очередной мотив моды: человек модный, которому важен хороший силуэт, форма и красота - значительно выше оценили старшие женщины $(9,80)$, чем младшие $(8,98)$. Аэробика в оценке молодых женщин в меньшем значении $(7,64)$ в отношении оценок старших женщин $(9,89)$ ассоциировала с успешными людьми, из среды бизнеса, культуры и средств массовой информации.

Мода была менее существенна среди молодых женщин $(8,84)$, чем старших $(9,67)$.

\section{Тип искателя приключений.}

В мнении молодых женщин $(9,03)$ аэробика имела большее значение в увеличении сил для борьбы с противоположностями и собственной слабостью, чем в мнении старших исследуемых $(8,34)$. Эстетика впечатлений имела немного меньшее значение среди младших респонденток $(8,44)$ чем старших $(7,15)$. Аэробика успокаивала эмоции среди младших $(7,98)$ и старших 
респонденток $(6,23)$. Похожее результаты заметны и в случае терапевтического действия. Этот аспект имел тоже немного более важное значение для женщин до 40 лет $(7,36)$, чем для женщин после 40 лет $(6,98)$. Сильные впечатления и эмоции связанные с аэробикой имели меньшее значение как для младших $(7,23)$ так и для старших исследуемых $(6,34)$.

Мотивы поиска приключений были более существенны в оценке младших респонденток $(8,08)$, чем респонденток после 40 лет $(7,01)$.
Аэробика как форма соревнования и соперничества.

Соперничество с собственными недочётами - это мотив более существенный среди женщин до 40 лет $(8,45)$, чем среди старших женщин $(7,86)$. Более важна была выгрузка агрессии среди женщин до 40 лет $(7,87)$, чем среди старших женщин $(5,67)$. Похожие результаты заметны в случае обучения снятия заторможенностей.

Вопросы соперничества и соревнования были более существенны среди младших $(7,56)$, чем старших респонденток $(6,69)$.

Таблица 1

Мотивы женщин к участию в занятиях аэробики.

\begin{tabular}{|c|c|c|c|c|c|}
\hline \multirow[t]{2}{*}{ № } & \multirow[t]{2}{*}{ Мотивировки к занятиям } & \multicolumn{2}{|c|}{19 - 40 лет } & \multicolumn{2}{|c|}{$41-50+$ лет } \\
\hline & & $\mathrm{H}$ & Средняя & $\mathrm{H}$ & Средняя \\
\hline \multicolumn{6}{|c|}{ Оздоровительно - гигиенические } \\
\hline 1. & Хорошее здоровье & 24 & 10 & 24 & 10 \\
\hline 2. & Соответствующая физическая чёткость & 24 & 10 & 24 & 10 \\
\hline 3. & Красивый силуэт & 24 & 10 & 24 & 10 \\
\hline 4. & Лучшая красота & 24 & 10 & 24 & 10 \\
\hline 5. & Хорошее самочувствие & 24 & 10 & 24 & 10 \\
\hline 6. & Удовлетворение необходимости отдыха и разрядки & 24 & 10 & 24 & 10 \\
\hline \multicolumn{2}{|r|}{ Средняя: } & \multicolumn{2}{|c|}{10} & \multicolumn{2}{|c|}{10} \\
\hline \multicolumn{6}{|c|}{ Общественно - товарищеские } \\
\hline 1. & Нужда функционирования в среде других людей & 24 & 9,91 & 24 & 8,45 \\
\hline 2. & Навязывание товарищеских контактов & 24 & 9,88 & 23 & 8,13 \\
\hline 3. & Групповые формы физической активности & 24 & 9,76 & 22 & 7,99 \\
\hline \multicolumn{2}{|c|}{ Средняя: } & \multicolumn{2}{|c|}{9,85} & \multicolumn{2}{|c|}{8,19} \\
\hline \multicolumn{6}{|c|}{ Формирования характера } \\
\hline 1. & Решимость & 24 & 9,87 & 24 & 9,76 \\
\hline 2. & Чувство собственной ценности & 24 & 9,60 & 24 & 9,11 \\
\hline 3. & Стойкость & 24 & 9,56 & 24 & 8,14 \\
\hline 4. & Устойчивость & 24 & 9,45 & 24 & 8,13 \\
\hline 5. & Систематичность & 24 & 9,34 & 24 & 8,97 \\
\hline 6. & Выдвигание более трудных целей & 24 & 9,19 & 24 & 8,13 \\
\hline 7. & Вера в собственные возможности & 24 & 8,96 & 24 & 9,30 \\
\hline 8. & Мужество & 24 & 8,74 & 24 & 9,56 \\
\hline \multicolumn{2}{|c|}{ Средняя: } & \multicolumn{2}{|c|}{9,33} & \multicolumn{2}{|c|}{8,89} \\
\hline \multicolumn{6}{|c|}{ Активности - гедонистические } \\
\hline 1. & Аэробика увлекательна и модная & 24 & 10 & 24 & 8,90 \\
\hline 2. & $\begin{array}{l}\text { Активность аэробики вытекает с биологичной нужды } \\
\text { движения }\end{array}$ & 24 & 9,87 & 23 & 7,18 \\
\hline 3. & Аэробика приятна & 24 & 8,98 & 20 & 6,15 \\
\hline 4. & $\begin{array}{l}\text { Выполняет эстетические нужды, а моё удовольствие } \\
\text { вытекает с эстетики жизни, действия }\end{array}$ & 24 & 8,19 & 24 & 5.87 \\
\hline \multicolumn{2}{|c|}{ Средняя: } & \multicolumn{2}{|c|}{9,26} & \multicolumn{2}{|c|}{7,02} \\
\hline \multicolumn{6}{|c|}{ Честолюбивые } \\
\hline 1. & Проверки самого себя для себя & 24 & 9,89 & 24 & 8,54 \\
\hline 2. & Получения признания и общественного одобрения & 24 & 9,78 & 24 & 5,98 \\
\hline 3. & Достижения совершенства на показ другим & 24 & 9,59 & 24 & 6,15 \\
\hline 4. & Увеличения собственного эго & 24 & 7,13 & 24 & 7,13 \\
\hline \multicolumn{2}{|c|}{ Средняя: } & \multicolumn{2}{|c|}{9,09} & \multicolumn{2}{|c|}{6,95} \\
\hline \multicolumn{6}{|c|}{ Релаксационные } \\
\hline & Аэробика разгружает стресс и напряжённость & 24 & 9,56 & 24 & 9,46 \\
\hline
\end{tabular}

ISPC Science and Education, 


\begin{tabular}{|l|l|l}
\hline & Аэробика внутренне очищает & \\
\hline & Аэробика способствует отдыху & \\
\hline $\begin{array}{l}\text { Аэробика является формой бегства от долгов и } \\
\text { проблем }\end{array}$ & \\
\hline & Аэробика служит как профилактика утомления & \\
\hline $\begin{array}{l}\text { Аэробика освобождает от ежедневных общественных } \\
\text { связей }\end{array}$ & \\
\hline Средняя: & \\
\hline
\end{tabular}

0.179

ESJI (KZ) $=1.042$

SJIF $($ Morocco $)=\mathbf{2 . 0 3 1}$

\begin{tabular}{|l|l|l|l|}
\hline 24 & 9,50 & 24 & 6,45 \\
\hline 24 & 9,13 & 24 & 8,89 \\
\hline 24 & 8,98 & 24 & 8,99 \\
& & & 8,13 \\
\hline 24 & 8,89 & 24 & 9,20 \\
\hline 24 & 8,13 & 24 & $\mathbf{8 , 5 2}$ \\
\hline
\end{tabular}

\begin{tabular}{|l|l|}
\hline \multicolumn{2}{|c|}{ Познавательно - воспи } \\
\hline 1. & Приобретаю умения, навыки активного образа жизни \\
\hline 2. & $\begin{array}{l}\text { Приобретаю знание о возможностях человеческой } \\
\text { природы }\end{array}$ \\
\hline 3. & Развиваю свои увлечения и пристрастия \\
\hline 4. & Выполняю процесс самодосконаленя \\
\hline 5. & Углубляю знание о ценности здоровья \\
\hline 6. & Изучаю новое \\
\hline Средняя:
\end{tabular}

Средняя:

тательные

\begin{tabular}{|c|c|c|c|c|c|}
\hline \multicolumn{6}{|c|}{ Мода } \\
\hline 1. & Активным стилем жизни & 24 & 9,89 & 24 & 9,32 \\
\hline 2. & $\begin{array}{l}\text { Модным человеком, который стремится к стройной } \\
\text { форме и красивому телу }\end{array}$ & 24 & 8,98 & 24 & 9,80 \\
\hline 3. & $\begin{array}{l}\text { Успешными людьми со сред бизнеса, культуры и } \\
\text { средств массовой информации }\end{array}$ & 24 & 7,64 & 24 & 9,89 \\
\hline \multicolumn{2}{|c|}{ Средняя: } & \multicolumn{2}{|c|}{8,84} & \multicolumn{2}{|c|}{9,67} \\
\hline
\end{tabular}

Искателя приключений

\begin{tabular}{|l|l|c|c|c|c|}
\hline 1. & $\begin{array}{l}\text { Доставляет силы к борьбе с препятствиями и } \\
\text { собственной слабостью }\end{array}$ & 23 & 9,03 & 24 & 8,34 \\
\hline 2. & Эстетические впечатления & 24 & 8,44 & 24 & 7,15 \\
\hline 3. & Приглушает эмоции ежедневного дня & 24 & 7,98 & 24 & 6,23 \\
\hline 4. & Действует как терапевтическое средство & 24 & 7,36 & 24 & 6,98 \\
\hline 5. & Сильных впечатлений и эмоций связанных с риском & 22 & 7,23 & 24 & 6,34 \\
\hline Средняя: & \multicolumn{2}{|c|}{$\mathbf{8 , 0 8}$} & \multicolumn{2}{|c|}{} \\
\hline
\end{tabular}
Средняя:

Соревнования и соперничества

\begin{tabular}{|l|l|c|c|c|c|}
\hline 1. & Соперничество с собственными недочётами & 24 & 8,45 & 24 & 7,86 \\
\hline 2. & Уменьшение агрессии & 24 & 7,87 & 24 & 5,67 \\
\hline 3. & Исключение заторможенностей & 20 & 6,38 & 24 & 6,55 \\
\hline Средняя: & \multicolumn{2}{|c|}{$\mathbf{7 , 5 6}$} & \multicolumn{2}{|c|}{$\mathbf{6 9}$} \\
\hline
\end{tabular}
Источник: собственная обработка

Факторы предпринятия в занятиях аэробики (табл. 2).

Экологические факторы способствующие активности в занятиях аэробики.

В мнении младших респонденток все экологические факторы: область, местность и качество аэробики в зависимости от места жительства были оценены в самой высокой степени. Похожие результаты аналогичны и в случае женщин после 40 лет.

Среднее значение экологических факторов показало, что молодые женщины (10) и старшие $(9,78)$ привязывали к ним большое внимание.

Личностные факторы.

Оказалось, что личностные факторы: состояние здоровья, нужды, заинтересованности, убеждения и суждения, пол, общая ступень активности, возраст, личные признаки были очень существенны среди обоих исследуемых

ISPC Science and Education,

Dijon, France

групп. Завоевали они в каждой категории выше 8 пкт. в масштабе до 10.

Также средняя исследований показала, что как младшие женщины $(9,67)$ так и старшие $(9,4)$ привязывали к ним очень большое внимание.

Биологичные факторы.

Исследуемые женщины в обоих возрастных группах привязывали существенное внимание к оздоровительным факторам. В десятибальном масштабе женщины в обоих группах признали выше 9,6 пкт. важности в случае биологических факторов: собственного здоровья, уровня чёткости и работоспособности.

Факторы

административно экономические.

Похожее результаты заметны в случае административно - экономических факторов: доступности занятий, количества свободного времени и материальной обстановки. 
Существенной разницей была материальная обстановка, которая как в оценке младших респонденток не имела существенного значения, так и среди старших женщин посещающих аэробику.

Однако все административно экономическое факторы были более важны (о 0,52 пункта.) среди женщин старше 40 лет.

Факторы приспособления к движению и общественной среды.

В случае факторов приспособления к движению и общественной среды: общественные нормы навязывающие двигательную активность и образование об двигательной активности были одинаково важны в мнении обоих исследуемых групп. Двигательная Активность в семье имела меньшее значение среди женщин старше 40 лет.

Исследования показали, что молодые женщины посещающие аэробику привязывали к
РИНЦ (Russia) $=0.179$

ESJI $(\mathrm{KZ}) \quad=\mathbf{1 . 0 4 2}$

SJIF $($ Morocco $)=\mathbf{2 . 0 3 1}$ факторам движения и общественной среды больший вес $(7,45)$, чем старшие женщины $(6,13)$.

Социологическо - экономические и общественные факторы.

Способствующим и самым существенным фактором для выполнения занятий в оценке младших респонденток была профессия и профессиональная активность $(9,60)$. Старшие респондентки этот фактор оценили немного ниже $(8,23)$. Прибыль и общественная структура в которой живут исследуемые респондентки имели похожее значение в мнении обоих исследуемых групп. Старшие респондентки приписывали высшую ценность образованию и семейному состоянию, чем их младшие респондентки.

Заметно было, что женщины до 40 лет $(8,25)$ к социологическо - экономическим и общественным факторам относились менее действительно, чем женщины после 40 лет $(9,05)$.

Факторы женщин к участию в занятиях аэробики.

Таблица 2

\begin{tabular}{|c|c|c|c|c|c|}
\hline \multirow[t]{2}{*}{ № } & \multirow[t]{2}{*}{ Факторы участия в занятиях аэробики } & \multicolumn{2}{|c|}{ 19-40 лет } & \multicolumn{2}{|c|}{$41-50+$ лет } \\
\hline & & $\mathrm{H}$ & Средняя & $\mathrm{H}$ & Средняя \\
\hline \multicolumn{6}{|c|}{ Экологические } \\
\hline 1. & Область жительства & 24 & 10 & 24 & 9,70 \\
\hline 2. & Местность жительства & 24 & 10 & 24 & 9,65 \\
\hline 3. & Качество доступности аэробики & 24 & 10 & 24 & 10 \\
\hline \multicolumn{2}{|c|}{ Средняя: } & \multicolumn{2}{|c|}{10} & \multicolumn{2}{|c|}{9,78} \\
\hline \multicolumn{6}{|c|}{ Личностные } \\
\hline 1. & Состояние здоровья & 24 & 10 & 24 & 10 \\
\hline 2. & Нужды, увлечения и желания & 24 & 10 & 24 & 8,90 \\
\hline 3. & Ориентация и взгляды & 24 & 9,90 & 24 & 9,40 \\
\hline 4. & Пол & 24 & 9,89 & 24 & 10 \\
\hline 5. & Общая ступень активности & 24 & 9,50 & 24 & 9,34 \\
\hline 6. & Возраст & 24 & 9,56 & 24 & 10 \\
\hline 7. & Личностные черты & 24 & 8,90 & 24 & 8,16 \\
\hline \multicolumn{2}{|c|}{ Средняя: } & \multicolumn{2}{|c|}{9,67} & \multicolumn{2}{|c|}{9,4} \\
\hline \multicolumn{6}{|c|}{ Биологические } \\
\hline 1. & Состояние здоровья & 24 & 10 & 24 & 10 \\
\hline 2. & Уровень чёткости, физической работоспособности & 24 & 9,68 & 24 & 9,78 \\
\hline 3. & Тип телосложения & 24 & 9,14 & 24 & 9,23 \\
\hline \multicolumn{2}{|c|}{ Средняя: } & \multicolumn{2}{|c|}{9,61} & \multicolumn{2}{|c|}{9,67} \\
\hline \multicolumn{6}{|c|}{ Административно - экономические } \\
\hline 1. & Доступность занятий аэробикой & 24 & 10 & 24 & 10 \\
\hline 2. & Количество свободного времени & 24 & 9,86 & 24 & 8,90 \\
\hline 3. & Материальная ситуация & 24 & 7,37 & 24 & 9,87 \\
\hline \multicolumn{2}{|c|}{ Средняя: } & \multicolumn{2}{|c|}{9,08} & \multicolumn{2}{|c|}{9,59} \\
\hline \multicolumn{6}{|c|}{ Приспособления к движению и общественной среды } \\
\hline 1. & $\begin{array}{l}\text { Общественные нормы навязывающие двигательную } \\
\text { активность }\end{array}$ & 24 & 9,14 & 24 & 8,95 \\
\hline 2. & Образование о двигательной активности & 24 & 8,24 & 24 & 8,28 \\
\hline 3. & Двигательная активность в семье & 24 & 7,45 & 24 & 6.13 \\
\hline \multicolumn{2}{|c|}{ Средняя: } & \multicolumn{2}{|c|}{7,45} & \multicolumn{2}{|c|}{6,13} \\
\hline
\end{tabular}

ISPC Science and Education, 


\section{Impact Factor:}

\begin{tabular}{|c|c|c|}
\hline SRA (India) & $=1.344$ & SIS (USA) \\
\hline ISI (Dubai, UAE & 0.829 & РИНЦ $($ Russia $)=0.179$ \\
\hline IF (Australia) & $=0.35$ & ESJI $(\mathrm{KZ})$ \\
\hline & $=1.500$ & SJIF $($ Morocco $)=\mathbf{2}$. \\
\hline
\end{tabular}

\begin{tabular}{|l|l|r|r|c|c|}
\hline 1. & Профессия и профессиональная активность & 18 & 9,60 & 24 & 8,23 \\
\hline 2. & Прибыль & 24 & 9,56 & 24 & 9,67 \\
\hline 3. & Структура общественная в которой живу & 20 & 9,17 & 24 & 9,43 \\
\hline 4. & Образование & 22 & 7,34 & 24 & 8,13 \\
\hline 5. & Семейное состояние & 24 & 5,60 & 24 & 9,78 \\
\hline Средняя: & \multicolumn{2}{|c|}{$\mathbf{9 , 2 5}$} & \multicolumn{2}{|c|}{} \\
\hline
\end{tabular}

Источник: собственная обработка

\section{Выводы и предложения}

Исследования проявили, что женщины до 40 лет оценивали важность мотивов от 10 пкт. до 7,56 пкт. Женщины после 40 лет оценивали мотивы от 10 пкт. до 6,69 пкт. Вследствие этого все мотивы для стремления к аэробике были более существенны в случае младших женщин $(8,99)$, в отношении к старшим женщинам $(8,17)$ (таб. 3).

Среди женщин до 40 лет преобладали мотивы здоровья - гигиенические; общественно товарищеские и формирования характера. Среди женщин после 40 лет главным образом способствовали мотивы здоровья гигиенические; моды; познавательные и воспитательные. Предварительная гипотеза, что в принятии упражнений аэробики ключевые были мотивы украшания тела и сохранения хорошего силуэта подтвердилась, так как исследуемые женщины наиболее высоко оценивали мотивы здоровья - гигиенические (хороший силуэт) и мотивы моды (красивое тело).

Анализ результатов проявил, что все факторы (средняя: 9,14) в оценке младших респонденток имели очень большое значение в принятии занятий. Оценили их с 10 до 8,25 пкт. Старшие респондентки тоже похоже оценили важность этих факторов $(9,21)$ оценивая их с 7,78 до 9,78 пкт.

Исследуемые женщины главным образом направлялись экологическими факторами. Младшие женщины обращали внимание на личностные и биологические факторы, старшие же обращали внимание на биологичческие и экономические факторы. Факторы доступности к занятиям принадлежат к группе факторов административно - экономических. Эти факторы оказались на четвёртом месте важности, но завоевали 10 пунктов к занятиям среди двух групп респонденток. Ведущие факторы принадлежали к группе экологических, следовательно гипотеза частично подтверждена.

Исследования проявили, что среди молодых и старших женщин самые существенные были факторы влияющие на стремление к аэробике. На втором месту нашлись мотивы к занятиям аэробики среди обоих исследуемых групп (табл. 3).

Таблица 3

Мотивы и факторы к участию в занятиях аэробики.

\begin{tabular}{|c|c|c|c|}
\hline \multirow[t]{2}{*}{ № } & \multirow[t]{2}{*}{ Мотивы участия в аэробике } & $\begin{array}{l}\text { Женщины: } \\
19-40 \text { лет }\end{array}$ & $\begin{array}{l}\text { Женщины: } \\
\text { 41-50+ лет }\end{array}$ \\
\hline & & Средняя & Средняя \\
\hline 1. & Оздоровительно - гигиенические & 10 & 10 \\
\hline 2. & Общественно - товарищеские & 9,85 & 8,19 \\
\hline 3. & Формирования характера & 9,33 & 8,89 \\
\hline 4. & Активности - гедонистические & 9,26 & 7,02 \\
\hline 5. & Честолюбивые & 9,09 & 6,95 \\
\hline 6. & Релаксационные & 9,03 & 8,52 \\
\hline 7. & Познавательно - воспитательные & 8,84 & 8,74 \\
\hline 8. & Мода & 8,84 & 9,67 \\
\hline 9. & Искателя приключений & 8,08 & 7,01 \\
\hline 10. & Соревнования и соперничества & 7,56 & 6,69 \\
\hline \multicolumn{2}{|c|}{ Средняя: } & 8,99 & 8,17 \\
\hline \multicolumn{4}{|c|}{ Факторы участия в аэробике } \\
\hline 1. & Экологические & 10 & 9,78 \\
\hline 2. & Личностные & 9,67 & 9,4 \\
\hline 3. & Биологичные & 9,60 & 9,67 \\
\hline 4. & Административно - экономические & 9,07 & 9,59 \\
\hline 5. & $\begin{array}{l}\text { Приспособления к движению и общественной } \\
\text { среды }\end{array}$ & 8,27 & 7,78 \\
\hline 6. & Социологическо - экономическое и & 8,25 & 9,05 \\
\hline
\end{tabular}

ISPC Science and Education, 


\begin{tabular}{|l|l|l|}
\hline общественные & & \\
\hline Средняя: & $\mathbf{9 , 1 4}$ & $\mathbf{9 , 2 1}$ \\
\hline
\end{tabular}

Источник: собственная обработка

Предложения:

1. Похожее исследование можно проводить среди участников разных спортивно рекреационных занятий. Вышеуказанное наверно помогло бы приготовить спортивно рекреационное предложение соответствующее нуждам потребителей.

2. Если факторы играют самое большое значение среди потребителей занятий, можно заключить, что улучшение предложения упражнений можно начать от анализа факторов и приспособления предложения к этому вопросу как главному и ведущему в клубах фитнесс.

3. Можно было б основать исследования в других возрастных группах. Возрастная перегородка до 40 лет и выше 40 может быть немного завышенной, так как нужды женщин до 26 года жизни могут быть совершенно другими в отношении к нуждам женщин уже в устабилизованых союзах и устойчивой профессиональной работе.

\section{References:}

1. Biernat E, Kozdroń E (2008) Rekreacja i turystyka szkolna w procesie edukacji, Wyższa Szkoła Edukacji w Sporcie, Warszawa: 55-58.

2. Demel M (1970) Teoria wychowania fizycznego. PWN, Warszawa.

3. Gracz J, Sankowski T (2001) Psychologia w rekreacji i turystyce, AWF, Poznań.

4. Kozłowska D, Ryszkowski W, Shved W, Wyszczelska - Oksień E, Sakowicz P (2012) Motywy podejmowania aktywności ruchowej w czasie wolnym studentów WSWFiT i studentów UwB w Białymstoku [w:] (red.) K.J. Sobolewski Roczniki Naukowe Wyższej Szkoły Wychowania Fizycznego i Turystyki w Białymstoku $\mathrm{Nr}$ 8. Dział Wydawnictw i Publikacji WSWFiT w Białymstoku, Białystok: 81-85. Available: https://depot.ceon.pl/handl e/123456789/7207

(Accessed: 02.08.2015).

5. Kozłowski S, Nazar K (1984) Wprowadzenie do fizjologii klinicznej, PZWL, Warszawa.

6. Nowak P F, (2012) Motywy zdrowotne w hierarchii wartości kobiet ćwiczących w klubach fitness. Medycyna Ogólna i Nauki o Zdrowiu 18.4. Lublin: 387-392.

7. Panina OV, Krivtsova MK, Podzorova MA (2014) THE METHODS OF THE PRODUCTIVITY ASSESSMENT OF THE ACTIVITY OF EXECUTIVE AUTHORITIES BY THE EXAMPLE OF THE USA AND
FINLAND. ISJ Theoretical \& Applied Science 9 (17): 116-119. Available:

doi:

http://dx.doi.org/10.15863/TAS.2014.09.17.19 (Accessed: 04.08.2015).

8. Perzyńska-Biskup A, Biskup L, Kapik-Gruca K i in. (2011) Motywy wybory aerobiku sportowego w środowisku młodzieży studenckiej. Молода спортивна наука України: зб. наук. пр. 3 галузі фіз. виховання, спорту i здоров'я людини / за заг. ред. Свгена Приступи. - Л.. Вип. 15, т. 2.: 195 - 200.

9. Schmitz-Scherzer R (1975) Psychologie heute, Freizeit, Gleichzeit.

10. Sikora A, Kaszuba J, Tomaszewska A (2012) Motywy podejmowania treningu Adua fitness przez kobiety w różnym wieku. Rozprawy Naukowe. Wrocław, Vol. 38: 26-32.

11. Tabak I (2005) Psychospołeczne aspekty aktywności fizycznej, AWF, Warszawa.

12. Winiarski R (1989) Wstęp do teorii rekreacji, AWF, Kraków.

13. Żychowska M, Żmigrodzki M, ̇̇ak M, Majchrzak A (2009) Sprawność fizyczna i motywacja kobiet wybierających aerobik jako formę rekreacji ruchowej. Zeszyty Naukowe Małopolskiej Wyższej Szkoty Ekonomicznej w Tarnowie, (3 (14)), Tarnów: 193-203. 